trigeminal nerve, which supplies the external pterygoid, is linked to the muscles of the oculomotor nerve and finally to the levator of the upper lid, forming the efferent arc. The condition is unilateral and it is usually more of cosmetic than functional importance.

${ }^{1}$ Garkal, R S, British fournal of Ophthalmology, 1961, 45, 566.

Coraya Hospital, Isfaham, Iran

S H MOSAVY, MD, FICA

M HORIAT, MD

\section{Early antenatal diagnosis of spina bifida in a twin fetus by ultrasonic examination and alpha-fetoprotein estimation}

The finding of raised alpha-fetoprotein $(\alpha-\mathrm{FP})$ levels in the amniotic fluid is the most common method for the early antenatal diagnosis of spina bifida. ${ }^{1}$ From a case of triplet pregnancy in which one fetus had an omphalocele, ${ }^{2}$ there is evidence that $\alpha$-FP can pass across the chorionic membrane, resulting in significantly raised $\alpha$-FP values in the amniotic fluid surrounding a normal fetus. This is a potential source of diagnostic error and may result in the termination of a normal twin fetus, whose mother has a reduced chance of having a normal child.

We have described the early antenatal diagnosis of spina bifida with ultrasound ${ }^{3}$ and report here on a patient with dizygotic twin fetuses that were discordant for spina bifida and which were correctly assessed at 17 weeks menstrual age by ultrasound examination and $\alpha-\mathrm{FP}$ estimation.

\section{Case report}

A 26-year-old Caucasian woman's first pregnancy in 1974 had resulted in the delivery of a girl with hydrocephalus and meningomyelocele; she died at the age of 12 days. In the present pregnancy ultrasonic examination was performed at the Central Middlesex Hospital at 14 weeks menstrual age and a twin pregnancy diagnosed. Amniocentesis was performed and the $\alpha-F P$ level was found to be $128 \mathrm{mg} / 1$, which is well above normal. ${ }^{4}$

A second ultrasonic examination was performed at Queen Charlotte's Hospital at 17 weeks; the membrane dividing the two amniotic sacs was identified (see figure, a) and amniotic fluid removed from both sacs by inserting a needle on each side of the membrane. Ultrasonic scanning to the right of the membrane showed a 17-week fetus with a dorsolumbar meningomyelocele (see figure, b and c). The fetus on the left, also 17 weeks in size, was diagnosed as being normal. The $\alpha$-FP level was raised in the fluid surrounding the right twin $(77.5 \mathrm{mg} / \mathrm{l})$ and normal in the fluid from the left $\operatorname{sac}(28.0 \mathrm{mg} / \mathrm{l})$.

The parents were told that a fetus with spina bifida had been identified but that the other twin was believed to be normal, and they decided to continue the pregnancy. Repeat ultrasonic examinations at 26 and 34 weeks showed increasing cerebral ventricular dilatation in the affected twin. The patient went into labour at 37 weeks but failed to progress and caesarean section was performed.

The right twin was hydrocephalic with a dorsolumbar spina bifida; this girl weighed $1820 \mathrm{~g}$. The left twin, also a girl, was apparently normal and weighed $2700 \mathrm{~g}$. Serological studies on both twins proved dizygosity. The abnormal twin died on the second day after delivery. The pathologist reported that the spina bifida affected D10 and L5 vertebral arches; the brain showed Arnold-Chiari malformation. The normal twin progressed well and subsequent paediatric examinations have confirmed a normal female child.

\section{Comment}

The success of amniotic fluid $\alpha$-FP determinations in this case contrasts with the false information leading to the termination of two normal fetuses in the case described by Nevin and Armstrong. ${ }^{2}$ These workers presented results from a triplet pregnancy with two sacs, one of which contained a fetus with exomphalos. Amniotic fluid $\alpha-\mathrm{FP}$ levels at 16 and 17 weeks showed a 3:1 and a 2:1 gradient respectively between the abnormal and normal sacs, but because of extremely high levels in the abnormal sac the levels in the other sac were above the normal range. In our case a similar (3:1) gradient in $\alpha-F P$ was found between the abnormal and normal sacs and $\alpha-F P$ estimation was
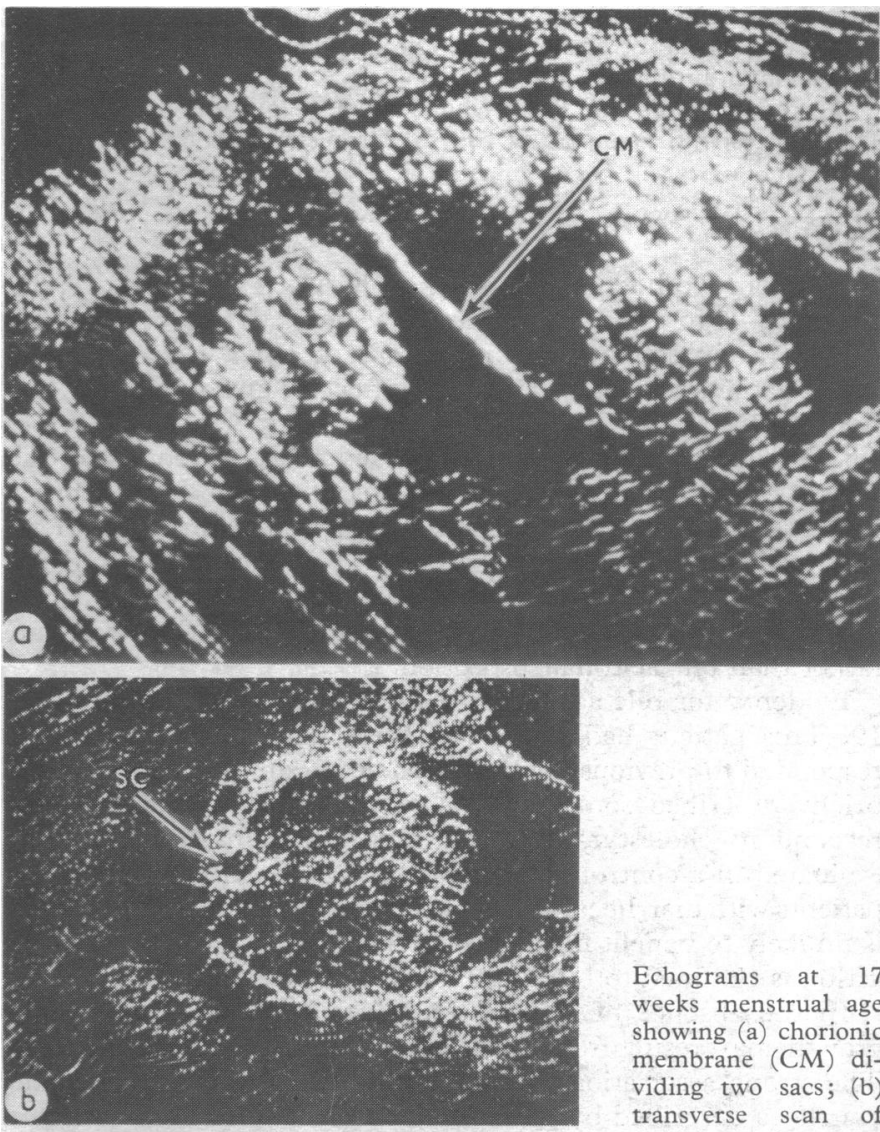

Echograms at 17 weeks menstrual age showing (a) chorionic membrane (CM) dividing two sacs; (b) transverse scan of fetal body in upper

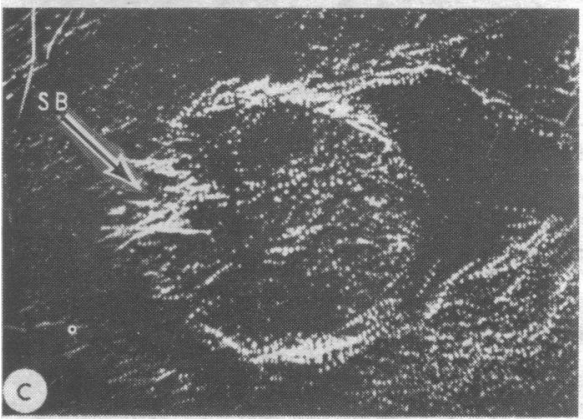

dorsal region showing circular outline of normal spinal canal (SC); and (c) transverse scan of fetal body in lower dorsal region showing the spina bifida $(\mathrm{SB})$.

successful only by virtue of the modest increase in values in the abnormal sac. This gradient is unlikely to occur when there is only amnion separating the sacs.

Ultrasound examination contributed to the successful outcome, by facilitating the removal of clear amniotic fluid from each sac and by identifying the extent of the spinal lesion in the affected fetus. To date 10 fetuses with spina bifida have been screened with ultrasound before 20 weeks in Queen Charlotte's Hospital; in seven cases the spinal defect was detected, the lowest lesion affecting vertebral arches L4 and 5 and the sacrum; three low lesions affecting vertebral arches $\mathrm{L} 5$ and the sacrum were not diagnosed. No false-positive diagnosis of spina bifida has been made by this technique.

${ }_{1}$ Brock, D J H, British Medical Bulletin, 1976, 32, 16.

2 Nevin, N C, and Armstrong, M J, British fournal of Obstetrics and Gynaecology, 1975, 82, 826

3 Campbell, S, et al, Lancet, 1975, 1, 1065

4 Seller, M J, et al, Lancet, 1974, 1, 428.

Institute of Obstetrics and Gynaecology, Queen Charlotte's Hospital, London W6 OXG

STUART CAMPBELL, FRCOG, professor

Central Middlesex Hospital, Acton Lane, London NW10

MICHAEL GRUNDY, MRCOG, senior registrar

Paediatric Research Unit, Guy's Hospital Medical School, London SE1

JACK D SINGER, MD, medical officer 